\title{
Synthesis and QSAR Studies of Novel Pyrazoline Derivatives as Antiproliferative Agent
}

\author{
Prafulla Madhukarrao Sable*, Nusrat Bhuru Ali Sayyad \\ Department of Pharmaceutical Sciences, Rashtrasant Tukadoji Maharaj Nagpur University, Nagpur, Maharashtra, INDIA.
}

\begin{abstract}
Background: Regardless of recent advances in the biological processes leading to the development of cancer, there is still a need for new and effective agents to help bring this disease under control. The revelation of the anticancer properties of pyrazoline makes this scaffold remarkable for research and development as an anticancer. Methods: A series of synthetic chalcones and pyrazoline derivatives were synthesized, characterized IR, ${ }^{1} \mathrm{H}$ NMR and mass spectral analysis and evaluated for their Anticancer activity on MCF-7 cell line through SRB assay. A QSAR study was performed on thirtyfive compounds of known series having pyrazoline nucleus using Accelrys Discovery Studio Vs 2.1.0.8130. Results: We found that significant inhibitory activity among all the synthesized compound 1B showing better anticancer activity having $\mathrm{IC}_{50}$ value 0.010 $\mu \mathrm{M}$ as compared to standard drug letrozole. So predicted molecules from the QSAR study show significant activity. Conclusion: We would conclude that compound 1B might serve as a potential antiproliferative agent.
\end{abstract}

Key words: Pyrazoline, OSAR, SRB assay, MCF-7, Antiproliferative activity.

\section{INTRODUCTION}

Cancer is known medically as a malignant neoplasm which is a broad group of various diseases involving unregulated cell growth. In cancer cells are dividing and grow uncontrollably resulted in malignant tumours and then invade nearby parts of the body. ${ }^{1}$ Behind cardiovascular disease, cancer is the second leading cause of death. ${ }^{2,3}$ Receptor protein tyrosine kinases transduce signal pathways that regulate cell division and differentiation. epidermal growth factor receptor (EGFR) kinase plays a key role in growth factors that have been identified as being important in cancer ${ }^{4,5}$ through studies of breast cancer suggest that 25-30\% of cases showed elevated expression of EGFR. Overexpression also was seen in lung cancer, ovarian cancer and prostate cancer. ${ }^{6,7}$ Compounds that inhibit EGFR kinase activity after binding cognate ligands are of potential interest as new therapeutic anticancer agents. ${ }^{8}$ Consequently, inhibition of the proliferative pathway is considered an effective approach in the battle against cancer. Different structural modifications of the pyrazoline motif have been made to explore its features/ properties and biological potential. ${ }^{9}$ Pyrazoline and its derivatives are recognized to possess a wide array of biological activities. The pyrazoline scaffold is the fundamental structure of many bioactive compounds. Pyrazoline shows different activities like anti-inflammatory activity, ${ }^{10}$ antiviral activity, ${ }^{11}$ antifungal activity, ${ }^{12}$ anticancer ${ }^{13}$ and antimicrobial activity. ${ }^{14}$ Significant attention was given to pyrazoline as an anticancer drug after the discovery and development of new anticancer agents. Quantitative structure-activity relationships (QSAR) and quantitative structure properties relationships (QSPR) play a central role in this effort and those methods are unquestionable of great importance in modern chemistry and biochemistry. ${ }^{15}$ The concept of QSAR/QSPR is to transform
Submission Date: 10-05-2020; Revision Date: 07-07-2020; Accepted Date: 07-09-2020

DOI: 10.5530/ijper.54.3s.161 Correspondence: Dr. Prafulla M Sabale Department of Pharmaceutical Sciences, Rashtrasant Tukadoji Maharaj Nagpur University, Nagpur-440033, Maharashtra, INDIA. Phone: +919158537050 E-mail: prafullasable@yahoo. com

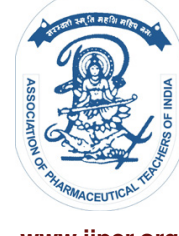

www.ijper.org 
searches for compounds with desired properties using chemical intuition and experience into a mathematically quantified and computerized form. QSAR attempts to correlate structural, chemical, statistical and physical properties with biological activity by various approaches. QSAR models are scientific credible tools for predicting and classifying biological activities of untested chemicals. QSAR is an essential tool for lead development (optimization); a growing trend is to use QSAR early in the drug discovery process as a screening and enrichment tool to eliminate from further development those chemicals lacking "drug-like" properties or those chemicals predicted to elicit a toxic response. ${ }^{16}$

\section{MATERIALS AND METHODS Materials and Instrumentation}

Melting points were determined using a VEEGO make microprocessor-based melting point apparatus having a silicone oil bath and are uncorrected. IR spectra (wavenumbers in $\mathrm{cm}^{-1}$ ) were recorded on a BRUKER ALPHA FT-IR spectrophotometer using Potassium bromide discs. NMR spectra were recorded on BRUKER AVANCE II $400 \mathrm{MHz}$ instrument in DMSO with TMS as an internal standard for ${ }^{1} \mathrm{H}$ NMR. Chemical shift values are mentioned in $\delta$, ppm. Mass spectra were recorded on Shimadzu LC-MS 2010 spectrometer. Chromatographic separations were performed on columns using silica gel 100-200 mesh. The progress of all reactions was monitored by TLC on $2 \mathrm{~cm} \mathrm{X} 5 \mathrm{~cm}$ pre-coated silica gel $60 \mathrm{~F}_{254}$ (Merck) plates of a thickness of $0.25 \mathrm{~mm}$. The chromatograms were visualized under UV $254 \mathrm{~nm}$ and/or exposure to iodine vapors. All reagents used were of analytical reagent grade, obtained from LOBA chemicals, SDFCL, Spectrochem and Sigma Aldrich. Chemicals and solvents were purified by general laboratory techniques before use. All moisturefree operations were performed in oven-dried glassware. The anti-cancer activity of all synthesized compounds will be evaluated for in-vitro measurement by MCF-7 cell line through SRB assay. QSAR study of pyrazoline as anticancer moiety was performed using Accelrys discovery studio client (Version 2.1) as the modelling tool. A total of 35 selected molecules were considered for the development of the QSAR model. The statistical analysis performed revealed following observations; $\mathrm{r}^{2}=0.884, \mathrm{r}^{2} \mathrm{cv}\left(\right.$ Cross validated $\left.\mathrm{r}^{2}\right)=0.883, \mathrm{r}^{2}$ pred $=$ 0.99 and $r^{2} \mathrm{~m}=0.61$. A total of 13 descriptors pruned on the study explained the structural correlation of pyrazoline. The model developed can be used to predict the bioefficacy of substituted pyrazoline derivatives as an anticancer agent. Based onthe QSAR study predicted molecules with different substituents are synthesized as per the following scheme Figure 1.

\section{Experimental}

A data set of pyrazoline derivatives reported by Ping et al. studied the synthesis and anticancer activity of 1-(5-(substitutedphenyl)-3-(substitutedphenyl)-4,5dihydropyrazol-1yl) ethanone derivatives were taken in form of $\mathrm{pIC}_{50}$. The total set of 35 compounds was randomly divided into a training set and a test set of 25 and 10 compounds, respectively. ${ }^{17}$ Chemical structures of the compounds along with the biological activity are shown in Table 1 and Table 2.

In this study, the $2 \mathrm{D}$ structure of the molecules was sketched on Chemdraw ultra 4.0 and the QSAR study of these series was done by Accelrys Discovery Studio Vs 2.1.0.8130. Discovery Studio is a single, powerful, easyto-use, graphical interface for drug design and protein modeling research. Discovery Studio 2.1 combines established gold-standard applications such as Catalyst, Modeler and CHARMm that have years of proven results and utilizes cutting-edge science to address the drug discovery challenges of today. Discovery Studio 2.1 is built on the Sci Tegic Enterprise Server platform to seamlessly integrate protein modeling, pharmacophore analysis, virtual screening and third-party applications.

All the structures first minimized by using energy minimization after that calculate molecular property of all minimized structure. Now based on all molecular property calculate the correlation matrix which gives a good correlation between two descriptors. A common practice in building QSAR models is to select descriptors that are not inter-correlated and show a lesser degree of multi-collinearity. This is achieved by determining the correlation between the independent variable (descriptor) of interest and other variables in the regression equation, with value 1 implying the highest multi-colinearity. Variance inflation factor (VIF) analysis is also determined and it should be less than 10. Selections of molecular descriptors for the QSAR study were carried out using the correlation matrix in excel and variance inflation factor analysis. The total numbers of 125 descriptors were calculated which included electronic, spatial, structural, thermodynamic, topological and geometric descriptors but some of them were rejected as they were highly correlated. Remaining descriptors were used to derive a QSAR model using the GFA technique. All the descriptors were calculated using PC based software, Discovery Studio 2.1 (Accelrys Inc, USA). Total 13 molecular descriptors such as Initial RMS Gradient, Improper Energy, Molecular_ 
FractionalPolarSASA, SIC, Dipole_Y, Jurs_RPCS, Minimized_Energy, Strain_Energy, RadofGyration, PMI_Z, Shadow_XY, Shadow_YZ, Shadow_Zlength. Table 3. One molecular property correlates with another molecular property which indicates such molecular property has a significant effect on molecules.QSAR models were generated using the GFA technique in Discovery studio 2.1 (Accelrys Inc, USA) shown in Table 4. The statistical qualities of models generated were judged by parameters such as Friedman's lack of fit measure (LOF), the square of regression coefficient $r^{2}$, adjusted $\mathrm{r}^{2}$ adj, cross-validated $\mathrm{r}^{2} \mathrm{cv}$ and standard deviation(s) as shown in Table 5.

There are two techniques to determine the reliability of the generated models, internal and external validation. Internal validation uses the dataset from which the model is derived and is required to check internal consistency and stability. To determine the quality of the model internally, cross-validation (cv) techniques are extensively employed. Cross-Validation methods employed for internal validation are Leave-One-Out, Leave-Some-Out, or Leave- Many-Out. The quality of the model is analyzed by the value of the correlation coefficient of the cross-validation procedure, that is, $\mathrm{r}^{2} \mathrm{cv}$. The commonly accepted value for a satisfactory QSAR model is $r^{2} \mathrm{cv}>0.5$. The most common approach of validation is to examine the residuals, i.e., calculated from the difference between observed and predicted biological activity. Lower the residual values better than the model. (Table 6, Figure 2)

The residue of the training set indicates the linearity of the model. The value of the residue gives an idea about the outlier of the selected series of the pyrazoline derivatives (Figure 2). More value of the residue deviated the biological activity.

\section{External Validation}

Any model with excellent statistical characteristics (like $\mathrm{r}^{2}, \mathrm{r}^{2} \mathrm{cv}, \mathrm{F}$-value) and satisfactory internal predictions may lack the true relationship between molecular descriptors and target property. To avoid chance correlation, a reliable validation procedure must be carried out. The ultimate validation of the model is examined utilizing external validation. The quality of a QSAR model is

\begin{tabular}{|c|c|c|c|c|c|}
\hline Sr. No. & Comp No. & $R_{1}$ & $R_{2}$ & $\mathrm{IC}_{50}$ & $\mathrm{plC}_{50}$ \\
\hline 1 & $1 \mathrm{a}$ & 3,4-di methyl & $4-F$ & 0.83 & 6.080922 \\
\hline 2 & $1 \mathrm{~b}$ & 3,4-di methyl & $4-\mathrm{Cl}$ & 1.36 & 5.866461 \\
\hline 3 & $1 \mathrm{c}$ & 3,4-di methyl & $4-\mathrm{Br}$ & 2.17 & 5.66354 \\
\hline 4 & $1 \mathrm{e}$ & 3,4-di methyl & $4-\mathrm{OCH}_{3}$ & 0.07 & 7.154902 \\
\hline 5 & $1 \mathrm{~g}$ & 3,4-di methyl & $4-\mathrm{NO}_{2}$ & 3.06 & 5.514279 \\
\hline 6 & $1 \mathrm{j}$ & 3,4-di methyl & $2-\mathrm{Br}$ & 4.21 & 5.375718 \\
\hline 7 & $1 \mathrm{k}$ & 3,4-dichloro & $4-\mathrm{F}$ & 6.27 & 5.202732 \\
\hline 8 & 11 & 3,4-dichloro & $4-\mathrm{Cl}$ & 7.32 & 5.135489 \\
\hline 9 & 10 & 3,4-dichloro & $4-\mathrm{OCH}_{3}$ & 5.74 & 5.241088 \\
\hline 10 & $1 \mathrm{t}$ & 3,4-dichloro & $2-\mathrm{Br}$ & 6.43 & 5.191789 \\
\hline 11 & $1 u$ & 3,4-dibromo & $4-F$ & 8.92 & 5.049635 \\
\hline 12 & $1 w$ & 3,4-dibromo & $4-\mathrm{Br}$ & 10.06 & 4.997402 \\
\hline 13 & $1 x$ & 3,4-dibromo & $4-\mathrm{CH}_{3}$ & 9.83 & 5.007446 \\
\hline 14 & $1 \mathrm{y}$ & 3,4-dibromo & $4-\mathrm{OCH}_{3}$ & 8.09 & 5.092051 \\
\hline 15 & $2 b$ & 3,4-dibromo & $2-\mathrm{F}$ & 13.37 & 4.874194 \\
\hline 16 & $2 d$ & 3,4-dibromo & $2-\mathrm{Br}$ & 10.97 & 4.959793 \\
\hline 17 & $2 f$ & 3,4-dichloro & $4-\mathrm{Cl}$ & 16.14 & 4.792096 \\
\hline 18 & $2 i$ & 3,4-dichloro & $4-\mathrm{OCH}_{3}$ & 17.19 & 4.74642 \\
\hline 19 & $2 \mathrm{j}$ & 3,4-dichloro & $2-\mathrm{Cl}$ & 24.15 & 4.617083 \\
\hline 20 & $2 \mathrm{k}$ & 3,4-dichloro & $4-\mathrm{H}$ & 28.69 & 4.542269 \\
\hline 21 & 21 & 3,4-dichloro & 3,5-Dimethoxy & 25.47 & 4.593971 \\
\hline 22 & $2 m$ & 3,4-dimethyl & $4-\mathrm{F}$ & 15.56 & 4.80799 \\
\hline 23 & 20 & 3,4-dimethyl & $4-\mathrm{Br}$ & 20.61 & 4.685922 \\
\hline 24 & $2 q$ & 3,4-dimethyl & $4-\mathrm{OCH}_{3}$ & 15.24 & 4.817015 \\
\hline 25 & $2 r$ & 3,4-dimethyl & $2-\mathrm{Cl}$ & 21.48 & 4.667966 \\
\hline
\end{tabular}


mostly determined by its ability to perform predictions of objects not included in the training sets. External validation of the QSAR model was carried out by examining the values of residuals, $r^{2}$ pred and $r^{2} \mathrm{~m}$ using test set compounds as shown in Table 7 . Based on the external validation, $\mathrm{r}^{2}$ predicted can be calculated which indicates the percent of predication of the selected model. Here outlier can be removed based on the value of the residue as shown in Figure 3

Prediction of novel compounds: For real validation, the biological activity of novel 35 compounds was predicted using equation 4. Among the predicted compounds, which exhibited potent activity will be synthesized. Table 8 shows a list of the predicted compounds having more predicted activity than observed activity in training and test set compounds.

\section{Chemical}

\section{General procedure and Spectral Characterization}

a) (A-C) Equimolar portions of the appropriately substituted aromaticaldehydes (10 $\mathrm{mmol}, 1$ equivalent) and ketones (10 mmol, 1 equivalent) were dissolved in approximately $15 \mathrm{~mL}$ of ethanol. The mixture was allowed to stir for several minutes at 5-10 $\mathrm{min}$. A $10 \mathrm{~mL}$ aliquot of a $40 \%$ aqueous potassium hydroxide solution was then slowly added dropwise to the reaction flask via a self-equalizing dropping funnel. The reaction solution was allowed to stir at room temperaturefor approximately $4 \mathrm{~h}$. Most commonly, a precipitate formedand was then collected by suction filtration. ${ }^{18}$

b) (1A-1C) pyrazoline derivatives were prepared by taking the solution of chalcone in acetic acid in the presence of hydrazine hydrate. Reaction undergo cyclization and form final compound $\mathbf{1 A - 1 C}$ which is confirmed by characteristic peak. ${ }^{19}$

1-(5-(3,4-Dimethoxyphenyl)-3-(3-hydroxyphenyl)4,5-dihydropyrazol-1yl) ethanone(1A)

Yield: $73.00 \%$; IR $\left(\mathrm{KBr}\right.$, in $\left.\mathrm{cm}^{-1}\right)$ : 3228.54(-OH), 2924.02(-OCH$)_{3}, 1742.18(-\mathrm{C}=\mathrm{O}), 1639.31(-\mathrm{C}=\mathrm{N}$ str.), 1416.06(-C-N str.); ${ }^{1} \mathrm{H}$ NMR (DMSO, $\delta$ in ppm): 6.677.22(m, 7H; Ar-H), 3.60(s, 3H; 3- $\left.\mathrm{OCH}_{3}\right), 3.23(\mathrm{~s}, 3 \mathrm{H}$;

\begin{tabular}{|c|c|c|c|c|c|}
\hline \multicolumn{7}{|c|}{ Table 2: Biological activities of test set compounds. } \\
\hline Sr No. & Comp No. & $\boldsymbol{R}_{\mathbf{1}}$ & $\boldsymbol{R}_{\mathbf{2}}$ & IC $_{50}$ & pIC $_{50}$ \\
\hline 1 & $1 \mathrm{~d}$ & 3,4-di methyl & $4-\mathrm{CH}_{3}$ & 0.34 & 6.468521 \\
\hline 2 & $1 \mathrm{i}$ & 3,4-di methyl & $2-\mathrm{Cl}$ & 3.87 & 5.412289 \\
\hline 3 & $1 \mathrm{~m}$ & 3,4-dichloro & $4-\mathrm{Br}$ & 6.85 & 5.164309 \\
\hline 4 & $1 \mathrm{n}$ & 3,4-dichloro & $4-\mathrm{CH}_{3}$ & 7.38 & 5.131944 \\
\hline 5 & $1 \mathrm{r}$ & 3,4-dichloro & $2-\mathrm{F}$ & 6.56 & 5.183096 \\
\hline 6 & $1 \mathrm{~s}$ & 3,4-dichloro & $2-\mathrm{Cl}$ & 7.28 & 5.137869 \\
\hline 7 & $1 \mathrm{v}$ & 3,4-dibromo & $4-\mathrm{Cl}$ & 8.15 & 5.088842 \\
\hline 8 & $2 \mathrm{a}$ & 3,4-dibromo & $4-\mathrm{NO}$ & 10.14 & 4.973058 \\
\hline 9 & $2 \mathrm{c}$ & 3,4-dibromo & $2-\mathrm{Cl}$ & 12.46 & 4.907982 \\
\hline 10 & $2 \mathrm{t}$ & 3,4-dimethyl & 3,5-Dimethoxy & 17.31 & 4.761703 \\
\hline
\end{tabular}

\begin{tabular}{|c|c|c|c|c|c|c|c|c|c|c|c|c|c|}
\hline & 1 & 2 & 3 & 4 & 5 & 6 & 7 & 8 & 9 & 10 & 11 & 12 & 13 \\
\hline 1 & 1 & & & & & & & & & & & & \\
\hline 2 & 0.207 & 1 & & & & & & & & & & & \\
\hline 3 & -0.410 & -0.182 & 1 & & & & & & & & & & \\
\hline 4 & -0.097 & 0.491 & -0.236 & 1 & & & & & & & & & \\
\hline 5 & -0.149 & 0.348 & 0.315 & 0.2761 & 1 & & & & & & & & \\
\hline 6 & 0.141 & -0.103 & 0.293 & -0.286 & -0.037 & 1 & & & & & & & \\
\hline 7 & 0.317 & 0.270 & 0.159 & 0.053 & -0.136 & 0.013 & 1 & & & & & & \\
\hline 8 & 0.050 & 0.170 & 0.180 & 0.378 & 0.476 & 0.034 & 0.167 & 1 & & & & & \\
\hline 9 & -0.205 & 0.039 & -0.269 & 0.302 & -0.398 & -0.071 & -0.110 & 0.0683 & 1 & & & & \\
\hline 10 & 0.151252 & -0.149 & 0.243 & -0.081 & 0.3178 & -0.029 & 0.244 & 0.150 & -0.462 & 1 & & & \\
\hline 11 & 0.093 & 0.258 & -0.356 & 0.411 & 0.054 & -0.151 & 0.068 & 0.168 & 0.459 & 0.309 & 1 & & \\
\hline 12 & -0.065 & -0.039 & 0.361 & 0.027 & 0.130 & -0.018 & 0.230 & 0.279 & 0.160 & 0.145 & -0.066 & 1 & \\
\hline 13 & -0.463 & 0.109 & 0.268 & 0.374 & 0.412 & -0.108 & -0.150 & 0.209 & -0.181 & 0.091 & -0.071 & 0.357 & 1 \\
\hline
\end{tabular}


$\left.\mathrm{OCH}_{3}\right), 1.96\left(\mathrm{~s}, 3 \mathrm{H} ; \mathrm{CH}_{3}\right), 3.94,3.69\left(\mathrm{dd}, 2 \mathrm{H} ; \mathrm{CH}_{2}\right)$, 4.59(s, $\left.{ }^{1} \mathrm{H} ; \mathrm{CH}\right), 9.43\left(\mathrm{~s},{ }^{1} \mathrm{H}, \mathrm{OH}\right) ;{ }^{13} \mathrm{C}$ NMR (DMSO, $\delta$ in ppm):151.7, 66.2, 39.9, 149.6, 147.8, 158.6, 135.4, 134.2, 109.8, 114.9, 121.9, 120.8,118.9, 118.2, 130.2, 164.5, 36.1, 56.1, 22.4; Exact mass: 340.14, Mass found : $341.14\left(\mathrm{M}^{+1}\right)$; Microanalysis: C, 67.05; H,5.92; N, 8.23; O, 18.80 .

\section{1-(5-(4-Chlorophenyl)-3-(4-ethoxyphenyl)-4,5-} dihydropyrazol-1-yl)ethanone (1B)

Yield : 75.44\%; IR ( $\mathrm{KBr}$, in $\left.\mathrm{cm}^{-1}\right)$ : 3286.70 (-NH str.), 3057.47(- $\left.-\mathrm{OC}_{2} \mathrm{H}_{5}\right), 1650.47(-\mathrm{C}=\mathrm{O}), 1598.92(-\mathrm{C}=\mathrm{N}$ str.), 1245.54(-C-N str.), 830.47(-Cl); ${ }^{1} \mathrm{H}$ NMR (DMSO, $\delta$ in ppm): 6.90-7.67(m, 8H; Ar- $H), 1.41-1.45\left(\mathrm{t}, 3 \mathrm{H} ; \mathrm{CH}_{3}\right)$, 4.04-4.09(q, 2H; $\left.\mathrm{CH}_{2}\right), 3.055-3.11(\mathrm{dd}, 1 \mathrm{H} ; \mathrm{CH}), 3.67-$ 3.74(q, 1H; $\mathrm{CH}), 5.50-5.54(\mathrm{dd}, 1 \mathrm{H} ; \mathrm{CH}), 2.39(\mathrm{~s}, 3 \mathrm{H}$; $\left.\mathrm{CH}_{3}\right) ;{ }^{1} \mathrm{C}$ NMR (DMSO, $\delta$ in ppm): 151.7, 65.9, 39.9, $132.3,161.7,128,139.1,128.5,114.5,128.3,127.3$, 128.6, 114.5, 127.2, 128.3,168.5, 64.6,23.4, 14.8; Exact mass:342.11, Mass found : $343.12\left(\mathrm{M}^{+1}\right)$; Microanalysis: C, 66.57; H, 5.59; Cl, 10.34; N, 8.17; O, 9.33.

1-(5-(3,4-Dimethoxyphenyl)-3-(2-hydroxyphenyl)4,5-dihydropyrazol-1-yl) ethanone (1C)

Yield: $66.05 \%$; IR $\left(\mathrm{KBr}\right.$, in $\left.\mathrm{cm}^{-1}\right): 3576.14 \mathrm{~cm}^{-1}$ $(-\mathrm{OH}), 2935.46 \mathrm{~cm}^{-1}\left(-\mathrm{OCH}_{3}\right), 1654.98 \mathrm{~cm}^{-1}(-\mathrm{C}=\mathrm{O})$, $1516.67 \mathrm{~cm}^{-1}\left(-\mathrm{C}=\mathrm{N}\right.$ str.) and $1256.02 \mathrm{~cm}^{-1}$ (-C-N str.); ${ }^{1} \mathrm{H}$ NMR (DMSO, $\delta$ in ppm): 6.67-7.22(m, 7H; Ar-H), $3.60\left(\mathrm{~s}, 3 \mathrm{H} ; 3-\mathrm{OCH}_{3}\right), 3.23\left(\mathrm{~s}, 3 \mathrm{H} ; \mathrm{OCH}_{3}\right), 1.96(\mathrm{~s}, 3 \mathrm{H}$; $\left.\mathrm{CH}_{3}\right), 3.94,3.69\left(\mathrm{dd}, 2 \mathrm{H} ; \mathrm{CH}_{2}\right), 4.59(\mathrm{~s}, 1 \mathrm{H} ; \mathrm{CH}), 9.73$ (s, $1 \mathrm{H}, \mathrm{OH}) ;{ }^{13} \mathrm{C}$ NMR (DMSO, $\delta$ in $\left.\mathrm{ppm}\right): 151.7,66.3,40.2$, 149.6, 147.8, 162.5, 118.6, 134.2, 109.8, 121.9, 117.8, 132.1, 118.9, 132.4, 121.4, 168.5, 56.1, 56.1, 23.4; Exact mass: 340.14 , Mass found : $341.4\left(\mathrm{M}^{+1}\right)$; Microanalysis: C, 67.05; H, 5.92; N, 8.23; O, 18.80

\section{Biological \\ SRB Assay}

Synthesized compounds were evaluated for aromatase inhibiting activity in SRB (Sulphorhodamine B) assay. For screening experiments, cells were inoculated into 96 well microtiter plates in $90 \mu \mathrm{L}$ at plating densities as shown in the study details above, depending on the doubling time of individual cell lines. After cell inoculation, the microtiter plates were incubated at $37^{\circ}$ C, $5 \% \mathrm{CO}_{2}, 95 \%$ air and $100 \%$ relative humidity for 24 $\mathrm{h}$ before the addition of experimental drugs. After $24 \mathrm{~h}$, one plate of each cell line was fixed in situ with TCA, to represent a measurement of the cell population for each cell line at the time of drug addition (Tz). Experimental drugs were solubilized in $0.1 \%$ DMSO at 400 -fold the desired final maximum test concentration and stored frozen before use. At the time of drug addition, an aliquot of frozen concentrate was thawed and diluted to
10 times the desired final maximum test concentration with complete medium containing test article at a concentration of $10^{-3}$. Additional three, 10-fold serial dilutions were made to provide a total of four drug concentrations plus control. Aliquots of $10 \mu \mathrm{l}$ of these different drug dilutions were added to the appropriate microtiter wells already containing $90 \mu \mathrm{l}$ of the medium, resulting in the required final drug concentrations. After compound addition, plates were incubated at standard conditions for 48 hours and the assay was terminated by the addition of cold TCA. Cells were fixed in situ by the gentle addition of $50 \mu \mathrm{l}$ of cold $30 \%$ (w/v) TCA (final concentration, $10 \% \mathrm{TCA}$ ) and incubated for 60 min at $4^{\circ} \mathrm{C}$. The supernatant was discarded; the plates were washed five times with tap water and air-dried. Sulforhodamine B (SRB) solution $(50 \mu \mathrm{l})$ at $0.4 \%(\mathrm{w} / \mathrm{v})$ in $1 \%$ acetic acid was added to each of the wells and plates were incubated for $20 \mathrm{~min}$ at room temperature. After staining, the unbound dye was recovered and the residual dye was removed by washing five times with $1 \%$ acetic acid. The plates were air-dried. The bound stain was subsequently eluted with a $10 \mathrm{mM}$ trizma base and the absorbance was read on an Elisa plate reader

\begin{tabular}{|c|c|}
\hline \multicolumn{2}{|c|}{ Table 4: List of QSAR equations. } \\
\hline Model No. & Coefficient of descriptor \\
\hline \multirow{4}{*}{1} & CHIRAG-6788-03 $=5.08633$ \\
& $0.0562951^{*}$ Minimized_Energy \\
& $+0.00510767{ }^{*}$ Molecular_Surface_Area_VAMP \\
$+0.00145385{ }^{*}$ PMI_Z \\
$+2.48078{ }^{*}$ RadOfGyration \\
$-0.146542{ }^{*}$ Shadow_XY
\end{tabular}




\begin{tabular}{|c|c|c|c|c|c|}
\hline \multicolumn{5}{|c|}{ Table 5: Statistical parameters of the generated models. } \\
\hline Model No & $\mathbf{r}^{2}$ & $\mathbf{r}^{2} \mathbf{c v}$ & LOF & $\mathbf{r}_{\text {pre }}$ & $\mathbf{r}_{\mathbf{m}}$ \\
\hline 1 & 0.909937 & 0.8933 & 0.996889 & 0.996912391 & 0.608535 \\
\hline 2 & 0.913729 & 0.9231 & 0.998193 & 0.99777934 & 0.646335 \\
\hline 3 & 0.896199 & 0.9522 & 1.110648 & 0.998022999 & 0.637878 \\
\hline 4 & 0.884230 & 0.8832 & 1.10936 & 0.996912716 & 0.61252 \\
\hline 5 & 0.898102 & 0.8321 & 1.16331 & 0.99656207 & 0.584498 \\
\hline
\end{tabular}

at a wavelength of $540 \mathrm{~nm}$ with a $690 \mathrm{~nm}$ reference wavelength.(3)

\section{Cell Culture}

The compounds were synthesized and evaluated for their invitro anticancer activity using SRB Assay against MCF-7 cell lines using letrozole as reference compound. This study was taken to determine the half maximal inhibitory concentration $\left(\mathrm{IC}_{50}\right)$ of bioactive compounds. The cytotoxic activity also evaluated against healthy vero cell of compounds $1 \mathrm{~A}, 1 \mathrm{~B}, 1 \mathrm{C}$, in order to express MCF-7 is a breast cancer cell line is the acronym of Michigan Cancer Foundation-7. MCF-7, cancer researchers can't obtain a mammary cell line that was capable of living longer than a few months. The cell lines were grown in RPMI (Roswell Park Memorial Institute) 1640 medium containing 10\% fetal bovine serum and $2 \mathrm{mM}$ L-glutamine. ${ }^{21}$

\section{RESULTS AND DISCUSSION}

For the preparation of targeted compound (1A1C) synthesis was planned as per the given scheme in which substituted acetophenone is reacted with a substituted aldehyde in presence of FDC40\% sodium hydroxide and Ethanol gave substituted chalcone which is further refluxed in presence of hydrazine hydrate and acetic acid to give the final product. After purification final compound was characterized by NMR spectroscopy, Mass spectrometry, IR spectroscopy. In IR spectroscopycompound A was confirmed at 1650 $\mathrm{cm}^{-1}$ (conjugated diene) by the reported procedure. ${ }^{10-11}$ The compound $1 \mathbf{A}$ was confirmed by the disappearance of the peak at $1655 \mathrm{~cm}^{-1}$ indicating conjugated dienes and shows 1639.31(-C=N), 1416.06(-C-N str.) in IR spectroscopy, ${ }^{1} \mathrm{H}$ NMR (DMSO, $\delta$ in ppm): 6.67-7.22(m, 7H; Ar-H), 3.60(s, 3H; 3- $\left.\mathrm{OCH}_{3}\right), 3.23\left(\mathrm{~s}, 3 \mathrm{H} ; \mathrm{OCH}_{3}\right)$, 1.96(s, 3H; $\left.\mathrm{CH}_{3}\right), 4.59(\mathrm{~s}, 1 \mathrm{H} ; \mathrm{CH}), 9.43(\mathrm{~s}, 1 \mathrm{H}, \mathrm{OH})$ in NMR spectroscopy, Molecular ion peak at341.4( $\left(\mathrm{M}^{+1}\right)$ in Mass spectroscopy. Compound $\mathrm{B}$ was confirmed at 3407.54 (-NH str.), 2977.67 $\left(-\mathrm{OC}_{2} \mathrm{H}_{5}\right), 815.22(-\mathrm{Cl})$ by the reported procedure. ${ }^{10-11}$ The compound $1 \mathrm{~B}$ was confirmed by the disappearance of the peak at $1657 \mathrm{~cm}^{-1}$ indicating conjugated dienes and shows 1598.92($\mathrm{C}=\mathrm{N}$ str.), 1245.54(-C-N str.), in IR spectroscopy, 3.67-3.74(q, $1 \mathrm{H} ; \mathrm{CH}), 5.50-5.54(\mathrm{dd}, 1 \mathrm{H} ; \mathrm{CH}), 2.39(\mathrm{~s}$, $3 \mathrm{H} ; \mathrm{CH}_{3}$ ) in NMR spectroscopy, molecular ion peak at $343.2\left(\mathrm{M}^{+1}\right)$ in Mass spectroscopy. Compound $\mathrm{C}$ was confirmed at $3434.26(-\mathrm{OH}), 2938.82\left(-\mathrm{OCH}_{3}\right)$ by the reported procedure. ${ }^{10-11}$ The compound $\mathbf{1 B}$ was confirmed by the disappearance of the peak at $1655 \mathrm{~cm}^{-1}$ indicating conjugated dienes and shows $3576.14(-\mathrm{OH})$, 2935.46(- $\left.\mathrm{OCH}_{3}\right), 1516.67(-\mathrm{C}=\mathrm{N}), 1256.02(-\mathrm{C}-\mathrm{N})$ in IR spectroscopy, 3.60(s, 3H; 3- $\left.\mathrm{OCH}_{3}\right), 3.23\left(\mathrm{~s}, 3 \mathrm{H} ; \mathrm{OCH}_{3}\right)$,

\begin{tabular}{|c|c|c|c|c|}
\hline Sr No. & Comp. No. & pIC $_{50}$ (obs.) & $\mathrm{pIC}_{50}$ (pre.) & Residue \\
\hline 1 & $1 \mathrm{a}$ & 6.080922 & 5.833 & -0.24792 \\
\hline 2 & $1 b$ & 5.866461 & 5.771 & -0.09546 \\
\hline 3 & $1 c$ & 5.66354 & 5.975 & 0.31146 \\
\hline 4 & $1 e$ & 7.154902 & 6.464 & -0.6909 \\
\hline 5 & $1 \mathrm{~g}$ & 5.514279 & 5.524 & 0.009721 \\
\hline 6 & $1 \mathrm{j}$ & 5.375718 & 5.458 & 0.082282 \\
\hline 7 & $1 \mathrm{k}$ & 5.202732 & 5.209 & 0.006268 \\
\hline 8 & 11 & 5.135489 & 5.205 & 0.069511 \\
\hline 9 & 10 & 5.241088 & 5.683 & 0.441912 \\
\hline 10 & $1 \mathrm{t}$ & 5.191789 & 4.947 & -0.24479 \\
\hline 11 & $1 u$ & 5.049635 & 5.044 & -0.00564 \\
\hline 12 & $1 w$ & 4.997402 & 5.046 & 0.048598 \\
\hline 13 & $1 x$ & 5.007446 & 5.062 & 0.054554 \\
\hline 14 & $1 y$ & 5.092051 & 5.215 & 0.122949 \\
\hline 15 & $2 b$ & 4.874194 & 5.251 & 0.376806 \\
\hline 16 & $2 d$ & 4.959793 & 4.758 & -0.20179 \\
\hline 17 & $2 f$ & 4.792096 & 4.574 & -0.2181 \\
\hline 18 & $2 i$ & 4.74642 & 4.772 & 0.02558 \\
\hline 19 & $2 \mathrm{j}$ & 4.617083 & 4.534 & -0.08308 \\
\hline 20 & $2 k$ & 4.542269 & 4.354 & -0.18827 \\
\hline 21 & 21 & 4.593971 & 4.438 & -0.15597 \\
\hline 22 & $2 m$ & 4.80799 & 4.754 & -0.05399 \\
\hline 23 & 20 & 4.685922 & 4.659 & -0.02692 \\
\hline 24 & $2 q$ & 4.817015 & 5.245 & 0.427985 \\
\hline 25 & $2 r$ & 4.667966 & 4.902 & 0.234034 \\
\hline
\end{tabular}




\begin{tabular}{|c|c|c|c|c|}
\hline \multicolumn{5}{|c|}{ Table 7: Results of external validation using equation 4. } \\
\hline Sr. No. & Comp. No. & plC $_{50}$ (obs.) & plC $_{50}$ (pre.) & Residue \\
\hline 1 & $1 \mathrm{i}$ & 5.412289 & 5.426 & 0.013711 \\
\hline 2 & $1 \mathrm{~m}$ & 5.164309 & 5.005 & -0.15931 \\
\hline 3 & $1 \mathrm{n}$ & 5.131944 & 5.009 & -0.12294 \\
\hline 4 & $1 \mathrm{r}$ & 5.183096 & 5.188 & 0.004904 \\
\hline 5 & $1 \mathrm{v}$ & 5.088842 & 4.998 & -0.09084 \\
\hline 6 & $2 \mathrm{c}$ & 4.907982 & 4.976 & 0.068018 \\
\hline 7 & $2 \mathrm{e}$ & 4.736364 & 4.792 & 0.055636 \\
\hline 8 & $2 \mathrm{n}$ & 4.705093 & 4.655 & -0.05009 \\
\hline 9 & $2 \mathrm{p}$ & 4.75721 & 4.642 & -0.11521 \\
\hline
\end{tabular}

\section{Table 8: List of the predicted compounds.}

\begin{tabular}{|c|c|c|c|c|}
\hline Sr. No. & Compound No. & $\mathbf{R}_{1}$ & $\mathbf{R}_{\mathbf{2}}$ & plC $_{50}$ \\
\hline 1 & 1A & 4-Ethoxy & 4-Chloro & $\mathbf{7 . 8 5 8}$ \\
\hline 2 & 1B & 2-Hydroxy & 3,4-Dimethoxy & $\mathbf{7 . 7 6 4}$ \\
\hline 3 & 1C & 3-Hydroxy & 3,4-Dimethoxy & $\mathbf{7 . 4 4 9}$ \\
\hline
\end{tabular}

\begin{tabular}{|c|c|c|c|c|c|}
\hline \multirow{2}{*}{ Table 9: Percent Cell growth inhibition data on MCF-7 cell line. } \\
\hline \multirow{2}{*}{ Concentration $(\boldsymbol{\mu g} / \mathbf{m l})$} & Log Conc. & \multicolumn{4}{|c|}{ \% Inhibition of Cell Growth } \\
\cline { 3 - 6 } & & Std. & 1A & 1B & 1 C \\
\hline 0.05 & -1.29 & -27.31 & -30.11 & -28.39 & -31.22 \\
\hline 0.15 & -0.82 & -21.25 & -28.44 & -25.88 & -30.89 \\
\hline 0.46 & -0.34 & -16.87 & -22.11 & 19.34 & -23.59 \\
\hline 1.37 & 0.14 & -10.89 & -13.55 & -10.12 & -15.39 \\
\hline 4.12 & 0.61 & -4.84 & -11.24 & -8.63 & -11.44 \\
\hline 12.35 & 1.09 & 3.36 & 6.55 & 15.55 & 7.83 \\
\hline 37.04 & 1.57 & 10.47 & 18.63 & 21.26 & 15.76 \\
\hline 111.11 & 2.05 & 17.32 & 25.96 & 29.64 & 22.64 \\
\hline 333.33 & 2.52 & 24.00 & 30.34 & 36.74 & 32.59 \\
\hline 1000.00 & 3.00 & 32.00 & 31.27 & 39.14 & 33.24 \\
\hline
\end{tabular}

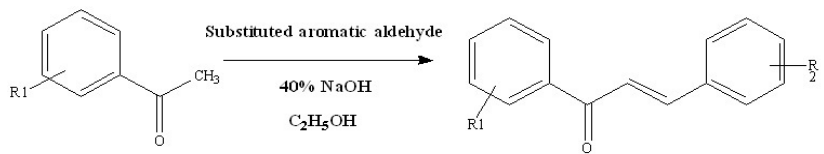

Sub.acetaphenone
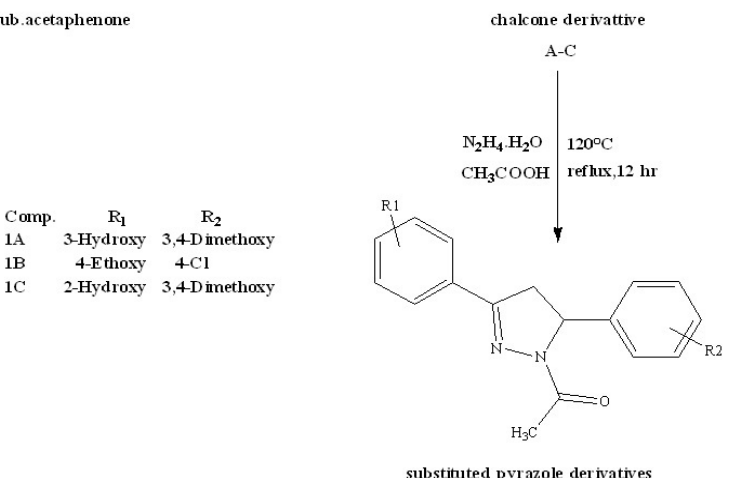

substituted pyrazole derivatives

$1 \mathrm{~A}-1 \mathrm{C}$

Figure 1: Schematic diagram for the synthesis of pyrazoline derivatives

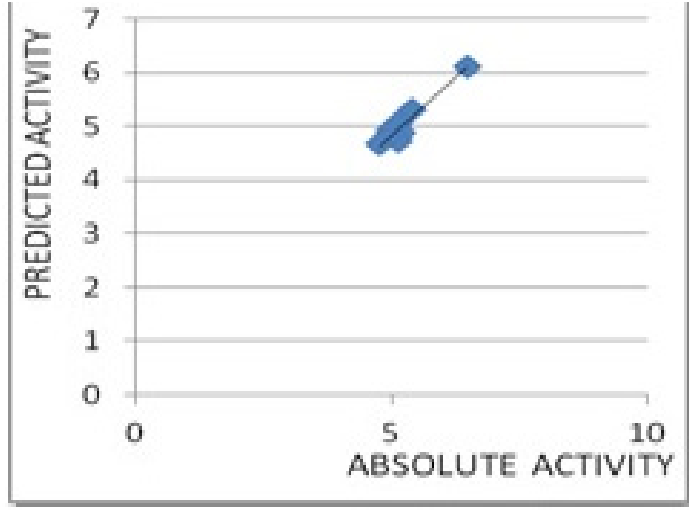

Figure 2: Graph of observed and predicted activities of the test set Compounds by Equation 4. 


\begin{tabular}{|c|c|c|c|c|c|c|c|}
\hline \multicolumn{7}{|c|}{ Table 10: IC } & value of synthesized compound. \\
\hline Compound & ${ }_{\mathrm{P}} \mathbf{I C}_{50 \mathrm{pre}}$ & $\mathrm{IC}_{50 \mathrm{pre}} \boldsymbol{\mu M}$ & ${ }_{\mathrm{P}} \mathbf{I C}_{50 \mathrm{obs}}$ & $\mathbf{I C}_{50 \mathrm{obs}} \boldsymbol{\mu M}$ & Residual & $\begin{array}{c}\mathbf{C C}_{50} \\
\text { Vero cell }\end{array}$ & SI \\
\hline 1A & 7.858 & 0.013 & 7.224 & $0.059 \pm 0.019$ & -0.63 & 85.12 & $\geq 1000$ \\
\hline 1B & 7.764 & 0.017 & 7.982 & $0.010 \pm 0.011$ & 0.218 & 72.78 & $\geq 1000$ \\
\hline 1C & 7.449 & 0.031 & 7.425 & $0.037 \pm 0.013$ & -0.024 & 77.35 & $\geq 1000$ \\
\hline Letrozole & & & & $0.025 \pm 0.01$ & & 89.47 & $\geq 1000$ \\
\hline
\end{tabular}

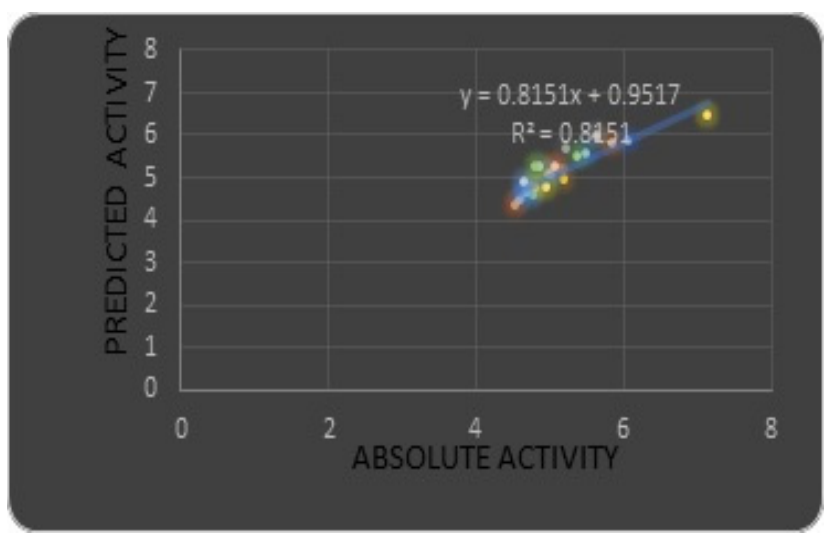

Figure 3: Graph of observed and predicted activities of the training set compounds by Equation 4.

3.02(s, 3H; $\left.\mathrm{CH}_{3}\right), 1.14$ (dd, 2H; $\left.\mathrm{CH}_{2}\right), 2.59(\mathrm{~s}, 1 \mathrm{H} ; \mathrm{CH}$ ), $9.73(\mathrm{~s}, 1 \mathrm{H}, \mathrm{OH})$ in NMR spectroscopy, Molecular ion peak at $341.4\left(\mathrm{M}^{+1}\right)$ in Mass spectroscopy. All of the synthesized compounds $(\mathbf{1 A}, \mathbf{1 B}, \mathbf{1 C})$ were evaluated for their aromatase inhibiting activity as shown in Table 9, activity was taken on MCF-7 cell line through SRB assay in which $\mathrm{IC}_{50}$ was calculated independently for every compound as shown in Table 10. Among all the synthesized compound $\mathbf{1 B}$ showing better anticancer activity having $\mathrm{IC}_{50}$ value $0.010 \mu \mathrm{Mas}$ compared to standard drug letrozole, compound 1B, compound 1C. compound $1 \mathrm{C}$ is having two methoxy group at $3^{\text {rd }}$ and $4^{\text {th }}$ position of an aromatic ring which is bulkier and sterically hindered compare to compound $\mathbf{1 B}$ and compound $\mathbf{1 A}$ hence it is least active, compound $\mathbf{1 A}$ is also having two methoxy group but are less sterically hindered than compound $\mathbf{1 C}$, compound $\mathbf{1 A}$ having only one electron-withdrawing group chloro at the para position of the aromatic ring which may be the possible reason for the significant activity.

\section{CONCLUSION}

The research work illustrates the attention to novel pyrazoline derivatives (1A-1C) representing anticancer agents through aromatase enzyme inhibition which involve in estrogen biosynthesis in breast cancer. The development of novel anticancer agent for the treatment of breast cancer through aromatase inhibition concludes that there is increasing need to develop novel derivatives which can inhibit aromatase enzyme which is crucial for estrogen synthesis in breast cancer.

\section{ACKNOWLEDGEMENT}

The authors are thankful to the Head, Department of Pharmaceutical Sciences, RTM Nagpur University, Nagpur for providing research facilities to carry out this research work. This activity has been carried out in collaboration with Dr. Arti S. Juvekar, Head of Screening department at Advanced Centre for Treatment Research and Education in Cancer (ACTREC), Khargarh, Mumbai.

\section{CONFLICT OF INTEREST}

Authors declare no conflict of interest in this research work.

\section{ABBREVIATIONS}

NMR: Nuclear magnetic resonance spectroscopy; TMS: Tetramethylselane; DMSO: Deuterated dimethyl sulfoxide; LC-MS: Liquid Chromatography-Mass Spectrometry; FT-IR: Fourier Transform infrared spectroscopy; SRB: Sulforhodamine B; QSAR: Quantitative Structure-activity relationship; TLC: Thin layer Chromatography.

\section{REFERENCES}

1. Pérez-Herrero E, Fernández-Medarde A. Advanced targeted therapies in cancer: Drug nanocarriers, the future of chemotherapy. Eur $\mathrm{J}$ Pharm Biopharm. 2015;93:52-79.

2. Chen J, Shen Y, Qian L, Chen L, Zheng K. 3D-QSAR of Benzothiazole Derivatives as Potent Anticancer Agents. Chin J Chem Phys. 2007;20(2):1359.

3. Gibbs JB. Mechanism-Based Target Identification and Drug Discovery in Cancer Research. Science. 2000;287(5460):1969-73.

4. Slamon D, Clark G, Wong S, Levin W, Ullrich A, McGuire W. Human breast cancer: correlation of relapse and survival with amplification of the HER-2/ neu oncogene. Science. 1987;235(4785):177-82.

5. Slamon D, Godolphin W, Jones L, Holt J, Wong S, Keith D, et al. Studies of the HER-2/neu proto-oncogene in human breast and ovarian cancer. Science. 1989;244(4905):707-12.

6. Gullick WJ. Prevalence of aberrant expression of the epidermal growth factor receptor in human cancers. Br Med Bull. 1991;47(1):87-98. 
7. Moscatello DK, Holgado-Madruga M, Godwin AK, Ramirez G, Gunn G. Frequent Expression of a Mutant Epidermal Growth Factor Receptor in Multiple Human Tumors. Cancer Research. 1995;55(23):5536-9.

8. Boschelli DH. Small molecule inhibitors of receptor tyrosine kinases. Drugs Future. 1999;24(5):515.

9. Varghese B, Al-Busafi SN, Suliman FO, Al-Kindy SMZ. Unveiling a versatile heterocycle: Pyrazoline: A review. RSC Adv. 2017;7(74):46999-7016.

10. Lokeshwari DM, Achutha DK, Srinivasan B, Shivalingegowda N, Krishnappagowda LN, Kariyappa AK. Synthesis of novel 2-pyrazoline analogues with potent anti-inflammatory effect mediated by inhibition of phospholipase A2: Crystallographic, in silico docking and QSAR analysis. Bioorg Med Chem Lett. 2017;27(16):3806-11.

11. Kumar S, Bawa S, Drabu S, Kumar R, Gupta H. Biological Activities of Pyrazoline Derivatives: A Recent Development. Recent Patents Anti-Infect Drug Disc. 2009;4(3):154-63.

12. Hassan S. Synthesis, Antibacterial and Antifungal Activity of Some New Pyrazoline and Pyrazole Derivatives. Molecules. 2013;18(3):2683-711.

13. Shaharyar M, Abdullah MM, Bakht MA, Majeed J. Pyrazoline bearing benzimidazoles: Search for anticancer agent. Eur J Med Chem. 2010;45(1):114-9.

14. Karthikeyan MS, Holla BS, Kumari NS. Synthesis and antimicrobial studies on novel chloro-fluorine containing hydroxy pyrazolines. Eur J Med Chem. 2007;42(1):30.
15. Garcia I, Fall Y, Gomez G. Review of Synthesis, Biological Assay and QSAR Studies of HMGR Inhibitors. Curr Top Med Chem. 2012;12(8):895-919.

16. Leonetti F, Favia A, Rao A, Aliano R, Paluszcak A, Hartmann RW, et al Design, Synthesis and 3D QSAR of Novel Potent and Selective Aromatase Inhibitors. J Med Chem. 2004;47(27):6792-803.

17. Alov P, Tsakovska I, Pajeva I. Computational Studies of Free RadicalScavenging Properties of Phenolic Compounds. Curr Top Med Chem. 2015;15(2):85-104.

18. Saxena H, Faridi U, Kumar J, Luqman S, Darokar M, Shanker K, et al. Synthesis of chalcone derivatives on steroidal framework and their anticancer activities 放. Steroids. 2007;72(13):892-900.

19. Solankee A, Patel G, Solankee S. Synthesis and studies of chalcones and its cyanopyridine and acetyl pyrazoline derivatives. Rasayan $\mathrm{J}$ Chem. 2008;5(1):591-5.

20. Hartmann RW, Bayer H, Gruen G. Aromatase Inhibitors: Syntheses and Structure-Activity Studies of Novel Pyridyl-Substituted Indanones, Indans and Tetralins. J Med Chem. 1994;37(9):1275-81.

21. Bhatnagar AS, Häusler A, Schieweck K, Lang M, Bowman R. Highly selective inhibition of estrogen biosynthesis by CGS 20267, a new non-steroidal aromatase inhibitor. J Steroid Biochem Mol Biol. 1990;37(6):1021-7.

\section{PICTORIAL ABSTRACT}

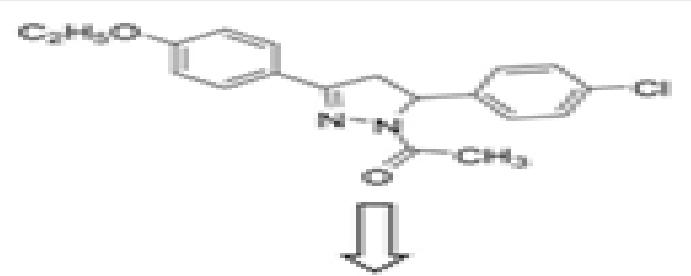

Prediched blotoriles activity through Gush. stunding

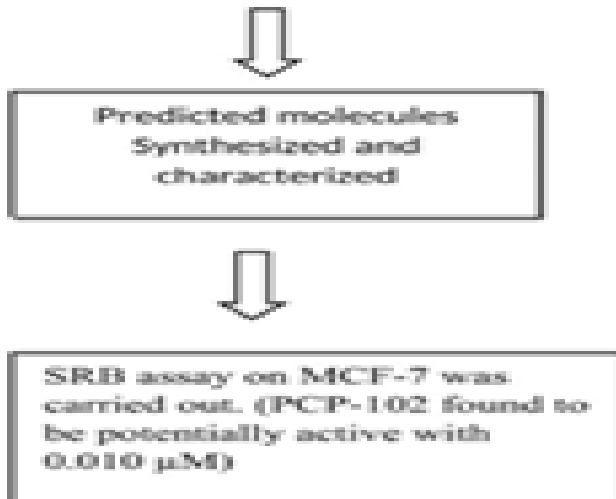

\section{SUMMARY}

- Being good pharmacophorepyrazolinefor anticancer series waswidely used for their potential in the present study.

- Some new 1-(5-(4-Chlorophenyl)-3-(4-ethoxyphenyl)4,5-dihydropyrazol-1-yl) ethanone potential against cancer cell line MCF-7activity having IC50value 0.010 $\mu \mathrm{M}$.

- OSAR study of pyrazoline as anticancer moiety was performed using Accelrys discovery studio client (Version 2.1) as the modelling tool. A total of 35 selected molecules were considered for the development of the QSAR model.

- The statistical analysis performed revealed following observations; $r 2=0.884, r 2 \mathrm{cv}$ (Cross validated $\mathrm{r} 2$ ) $=0.883, \mathrm{r} 2$ pred $=0.99$ and $\mathrm{r} 2 \mathrm{~m}=0.61$. A total of 13 descriptors pruned on the study explained the structural correlation of pyrazoline. 


\section{About Authors}

Dr. Prafulla M. Sabale is a Professsor at Department of Pharmaceutical Sciences and currently working as The Director, Board of Examination \& Evaluation, RTM Nagpur University, Nagpur. He is having total 23 years of experience in teaching, research and administration. Dr. Sabale is a Central Council member of Pharmacy Council of India, New Delhi, nominated u/s. 3(a) by the University Grants Commission. He has completed his M. Pharm and Ph.D. from Pharmacy Department, The M. S. University of Baroda, Vadodara. He has received grants from AICTE, UGC, GUJCOST and URPS. He was the recipient of Young Gandhian Technological Award in the year 2011. To his credit Dr Sabale has several research papers in various journals of national and international repute. He has been granted one Indian Patent and filed three more patents. He is life member of several professional bodies such as FIC, APTI, IPA, ISTE, SPER, ISCA, NSI etc.

Ms. Nusrat Sayyad has completed her master's degree from National Institute of Pharmaceutical Education and Research, Hyderabad. Currently she is pursing Ph D at Department of Pharmaceutical Sciences, RTM Nagpur University, Nagpur, Maharashtra, India. Her area of research interest is Heterocyclic Chemistry.

Cite this article: Sabale PM, Sayyad NB. Synthesis and QSAR Studies of Novel Pyrazoline Derivatives as Antiproliferative Agent. Indian J of Pharmaceutical Education and Research. 2020;54(3s):s610-s619. 